\title{
Challenges and Prospects of Mother Tongue Instructional Policy in Osun State ECCDE Centres
}

\author{
Okewole, Johnson Oludele (Ph.D) \\ Osunjimi, Lawrence Adebayo (Ph.D) \\ Institute of Education, Obafemi Awolowo University \\ Ile-Ife, Osun State \\ Nigeria
}

\begin{abstract}
Abstact
Many education systems favour using national or 'global' languages instead of mother-tongue. Education is often carried out in the old colonial language, or an international language, such as English. This is based on the belief that certain internationally 'important' languages give children a competitive advantage in later life. In other countries, education is taught in the dominant language of a main linguistic group, sometimes at the expense of more marginalized ethnic or linguistic groups This paper, therefore, examined the challenges and prospects of mother tongue instructional policy in Osun State Early Childhood Care and Development Education.The design of the study was descriptive.Four ECCDE centres were sampled from each of the Ife East, Ife North and Ife South LGAs and five from Ife central LGA (due to its cosmopolitan nature) by convenience to participate in the study. The study sample consists of 107 participants selected by convenience. The instrument used in this study was a self-constructed Questionnaire titled "Questionnaire on Challenges and Prospects of Mother Tongue Instructional Policy in Osun state ECCDE centres (QCPMTIP)".From the foregoing it is evident that the Mothe Tongue instructional policy is not being properly implemented in ECCDE centres in Ife Zone of Osun state. Reasons found for this include the disposition of the government, parents and the owners as well as the operators of such centres.
\end{abstract}

Keywords: Early childhood care and education, mother tongue, instructional policy and pre-schoolers.

\section{Introduction}

Early Childhood Education is very essential in the life of a child's hence the recent focus on its desirability across the globe. It provides for children whose age bracket is from 0- 8 years. A period described by Osanyin (2002) as extremely crucial to an individual's intellectual, emotional, social and physical development. This are the most impressionable years as they lay the foundation for the development of the human personality. More so, it is a stratum which the Mother Tongue (MT) will make a significant impression in the life of the young ones. Mother tongue, as the term suggests, is closest to a person's heart. Like mother's touch and mother's milk, it can never find a substitute. To this end, modern psychology also lays tremendous stress on a child's connection with the mother tongue.

The significance of the MT Education in early childhood development, accounts for the series of International conferences and conventions notable amongst which is the 1990 convention to the Right of the Child, World conference on Education For All (EFA), in Jomtien in 1990 and EFA Summit in New Delhi in 1993 respectively and OAU International Conference on Assistance to Africa Children. At the various congregations the child became a "Priority". Right of the child to free and compulsory education an obligation of the state was canvassed and especially it provides stimulus for government to take action on the right of the child in connection with the Mother Tongue. Corroborating the above position Osanyin (2002) reported that the convention states specifically that every person shall be able to benefit from educational opportunities designed to meet the basic learning needs. The needs comprise both essential learning tools such as literacy, oral expression, numeracy and problem solving and the basic learning content such as knowledge, skills, values and activities required to survive and develop to full capacity. Against this background, UNESCO in 1999 declared February 21-22 of every year as International Mother Tongue Day. The inter relatedness and strong relationship that exist between the two concept that is Early Childhood Education and mother tongue cannot be overemphasized.

Fafunwa (1978) however established through research that the best language for good concept formation at a very tender age is the indigenous language. The research was conducted in 1970, at the Institute of Education of the University of Ife (now Obafemi Awolowo University, Ile- Ife) in Osun State of Nigeria. 
The 'Ife Six-Year Primary Project' was designed to use Yoruba language as a medium of instruction in primary schools in Osun State of Nigeria. This project was based on the premise that:

(a) the child will benefit culturally, socially, linguistically and cognitively.

(b) the child's command of English will be improved if he is taught English as an entirely separate subject by a specialist teacher through the six years.

\section{Objectives of the Study}

The main objective of the study is to explore the challenges and prospects of the mother tongue instructional policy in Osun ECCDE centres.

The specific objectives of the study are to:

a. identify the level of awareness of ECCDE centre operators concerning mother tongue instructional policy with regard to early childhood education.

b. survey the operational practices adopted by the ECCDE centres in implementing the mother tongue education provisions in the national policy

c. identify the challenges encountered by ECCDE centre management/operators in the implementation of the Mother tongue instructional policy.

d. investigate the disposition of the parents and ECCDE centre operators toward the mother tongue instructional policy.

\section{Research Questions}

1. What are the levels of awareness of ECCDE centre operators concerning Mother tongue instructional policy?

2. What operational practices are adopted by the ECCDE centres in implementing the mother tongue instructional policy?

3. What are the challenges encountered by ECCDE centre management/operators in the implementation of the Mother tongue instructional policy.

4. What are the disposition of the parents and ECCDE centre operators toward the mother tongue instructional policy?

\section{Delimitation of the Study}

The study was designed to cover one of the local government areas of Osun state - Ife central for the sake of convenience, cost-effectiveness and time efficiency.

\section{Research Methodology}

The design of the study was descriptive. Best (1978) posited that a descriptive study is concerned with conditions or relationships that exists, opinion that are held, processes that are going on, effects that are evident or trends that are developing. It is primarily concerned with the present, although it often considers the past events and influences as they relate to current conditions The target population for this study consisted of all the managers and operators of ECCDE centres in four selected Local Government Areas (LGAs) of Osun state. The Ife Zone consists of LGAs - Ife Central, Ife East, Ife North and Ife South LGAs. Four ECCDE centres were sampled from each of the Ife East, Ife North and Ife South LGAs and five from Ife central LGA (due to its cosmopolitan nature) by convenience to participate in the study. The study sample consists of 107 participants selected by convenience. This comprises the owners/owners-operators as well as five care-givers also selected by convenience from each of the selected centres. The instrument used in this study was a self-constructed Questionnaire titled "Questionnaire on Challenges and Prospects of Mother Tongue Instructional Policy in Osun state ECCDE centres (QCPMTIP)". It consists of four major sections. Section A seeks for the biographical information of the respondents while Section B consisting of items which sought to obtain information from the respondents concerning the challenges they confront in implementing the mother tongue instructional policy in the ECCDE centres. This section is formatted into Likert-type response format of Strongly agree, Agree, disagree and strongly disagree. Section $\mathrm{C}$ contains items designed to obtain information from the respondents about the prospects of implementing the mother tongue instructional policy in the ECCDE centres. The validity of the instruments was determined through expert judgment. The instrument was submitted to the supervisor and experts in Tests and Measurement in the Faculty to help determine that the instrument is good enough to explore the implementation of the mother tongue instructional policy in the ECCDE centres. To obtain the reliability, each of the instruments was administered on an intact group of 20 operators in Atakumosa East LGA as they were not involved in the study proper. The resulting respondents' responses were used to obtain the internal consistency reliability Cronbach's alpha $=0.88$ and split - half $=0.83$. 
The questionnaire was administered on the owners, operators and care-givers of the selected ECCDE centres across the four local government areas by the researchers, sometimes assisted by the manager of the ECCDE centres where the study took place. Data collected for the study were scored and coded into Microsoft Excel and SPSS softwares for appropriate computer analysis. The data were analyzed using descriptive statistics, Relative Significance Index (RSI) in reference to its superior performance demonstrated by Adebowale and Ojo (2009) for prevalence data.

\section{Results}

Research Question 1: What is the level of awareness of ECCDE centre operators concerning Mother tongue instructional policy?

The responses to items in the section B were scored in such a way that VS carries 4, QA carries 3 and MB was allotted 2 while NA was scored 1 . The resulting scores were cumulated and used to build a measure of respondents' awareness of the provisions of the mother tongue instructional policy. The mean score was 12.41 with standard deviation score of 3.27. Those who score 7 or less on this measure were said to possess low level of awareness, while those who scored 8 to 11 were said to have a moderate level of awareness and those who score more than 11 were said to possess high level of awareness. These categories were further given a descriptive analysis and the result is shown in Table 1 below.

Table 1: Level of awareness of the provisions of the mother tongue instructional policy

\begin{tabular}{|l|l|l|}
\hline Level of awareness & Frequency & Percent \\
\hline Low level & 11 & 10.28 \\
\hline Moderate level & 27 & 25.23 \\
\hline High level & 69 & 64.49 \\
\hline Total & 248 & 100.0 \\
\hline
\end{tabular}

Table 1 shows the descriptive analysis of the level of awareness of the provisions of the Mother Tongue instructional policy among the operators of the ECCDE centres under study. From the Table it can be seen that most of the respondents (64.49\%) possess high level of awareness of the policy provisions while $25.23 \%$ possess a moderate level of awareness. Only $10.28 \%$ possess low level of awareness of the provisions of the mother tongue instructional policy.

Research Question 2: What operational practices are adopted by the ECCDE centres in implementing the mother tongue instructional policy?

To answer this research question, the operators' responses to the section B of the questionnaire were given a descriptive analysis and the result is presented in Table 2. Table 2 presents the operational practices that are adopted by the ECCDE centres under study in implementing the mother tongue instructional policy. It can be seen from the table that it cannot be said that the mother tongue instructional policy are been implemented in ECCDE centres under study. For instance most of the respondents $(77.57 \%$ ) disagreed (either merely or strongly) with the statement that all the children were being taught all subjects in the local language of their communities - Yoruba language. Only $7.5 \%$ of the respondents strongly agreed while $14.95 \%$ merely agreed. In some cases some of the respondents indicated (strongly or merely) that they teach some subjects in Yoruba language while the majority disagreed. Most (91.59\%) even indicated (strongly or merely) that they find it difficult to teach colours, shapes and forms in the local language while some others indicated that the parents disallow the implementation of the mother tongue instructional policy.

Table 2: Operational practices adopted by the ECCDE centres in implementing the mother tongue instructional policy

\begin{tabular}{|c|c|c|c|c|c|c|c|c|c|}
\hline SN & Statement & \multicolumn{2}{|c|}{ SA } & \multicolumn{2}{|l|}{ A } & \multicolumn{2}{|l|}{$\mathrm{D}$} & \multicolumn{2}{|c|}{ SD } \\
\hline 1 & All the children in this centre are taught all subjects in Yoruba language & 8 & 7.48 & 16 & 14.95 & 30 & 28.04 & 53 & 49.53 \\
\hline 2 & $\begin{array}{l}\text { In this centre we teach only the rudiments of numbers, letters in Yoruba and } \\
\text { others in English language }\end{array}$ & 19 & 17.76 & 23 & 21.50 & 29 & 27.10 & 36 & 33.64 \\
\hline 4 & $\begin{array}{l}\text { The children are taught in English when their parents are around and later in } \\
\text { Yoruba language }\end{array}$ & 10 & 9.35 & 21 & 19.63 & 34 & 31.78 & 42 & 39.25 \\
\hline 5 & Parents do not allow the use of mother tongue in teaching their children & 89 & 83.18 & 10 & 9.35 & 4 & 3.74 & 4 & 3.74 \\
\hline 7 & $\begin{array}{l}\text { The management of this centre do not allow the use of local language when } \\
\text { teaching the children }\end{array}$ & 33 & 30.84 & 29 & 27.10 & 25 & 23.36 & 20 & 18.69 \\
\hline 8 & The textbook required for teaching the children are not written in Yoruba & 87 & 81.31 & 13 & 12.15 & 4 & 3.74 & 3 & 2.80 \\
\hline 9 & $\begin{array}{l}\text { Some parents who are not from Yoruba land vehemently opposed teaching their } \\
\text { children in Yoruba language }\end{array}$ & 79 & 73.83 & 20 & 18.69 & 5 & 4.67 & 3 & 2.80 \\
\hline 10 & Most of the teachers in this centre don't understand Yoruba language & 12 & 11.21 & 21 & 19.63 & 36 & 33.64 & 38 & 35.51 \\
\hline
\end{tabular}


Research Question 3: What are the challenges encountered by ECCDE centre management/operators in the implementation of the Mother tongue instructional policy. To answer this research question, the section $\mathrm{C}$ of the questionnaire was given a descriptive analysis and the result is presented in Table 3.

Table 3 shows the challenges the ECCDE centre operators confront in implementing the mother tongue instructional policy. It can be seen from the table that the most noticeable ones are from the government, the centre owners and the parents. For instance it can be seen that most of the respondents $(81.31 \%)$ indicated that the government has just been paying lip service to the implementation of the policy; that $(73.3 \%)$ whenever officials from the monitoring and inspectorate unit visited, they do not insist on the implementation of the policy. They also indicated (83.18\%) that since the centres are mostly privately owned with basic interest being the income, and parents vehemently resisting teaching their children and ward in mother tongue (63.55\%), it may be difficult to implement the policy in their centres.

Table 3: Challenges encountered by ECCDE centre management/operators in the implementation of the Mother tongue instructional policy

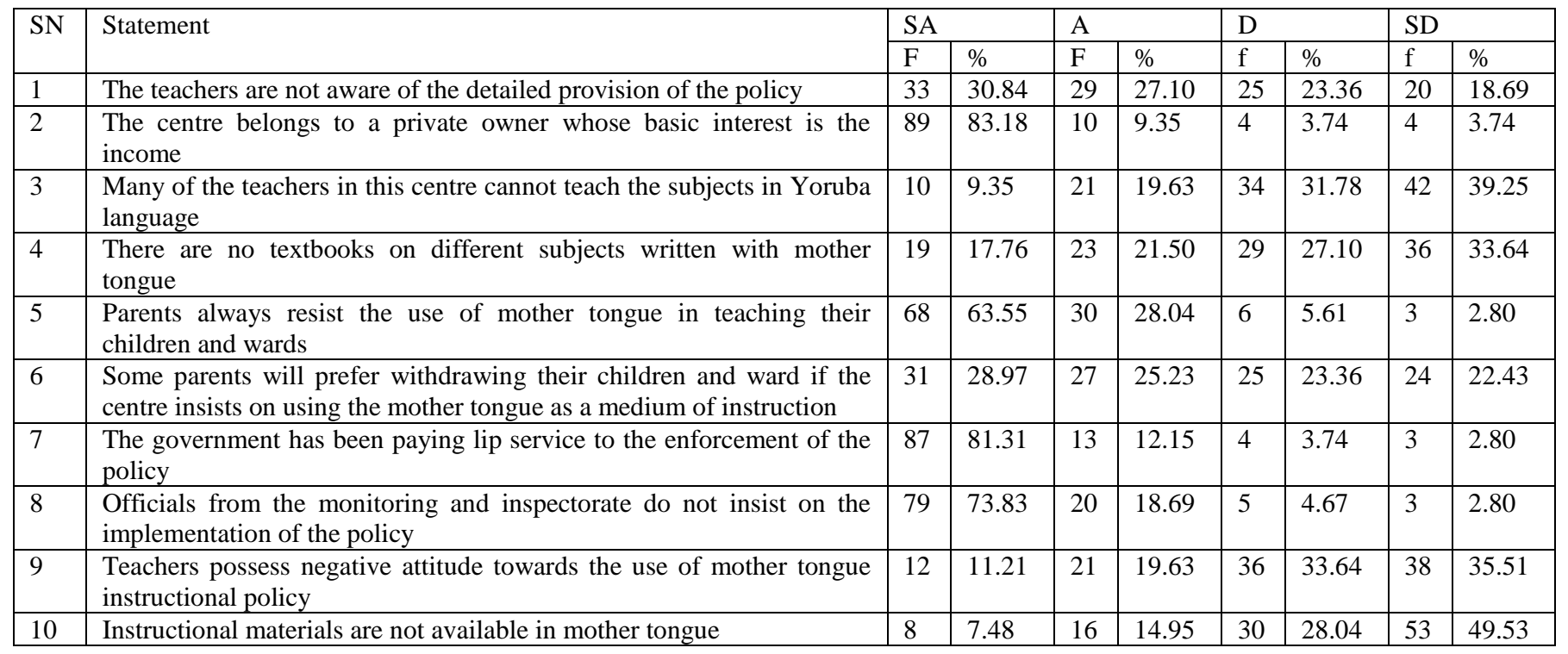

Research Question 4: What are the disposition of the parents and ECCDE centre operators toward the mother tongue instructional policy?

To answer this research question, the section D of the questionnaire was given a descriptive analysis and the result is presented in Table 4.

Table 4: Disposition of the parents and ECCDE centre operators toward the mother tongue instructional policy?

\begin{tabular}{|c|c|c|c|c|c|c|c|c|c|}
\hline \multirow[t]{2}{*}{$\mathrm{SN}$} & \multirow[t]{2}{*}{ Statement } & \multicolumn{2}{|l|}{ SA } & \multicolumn{2}{|l|}{$\mathrm{A}$} & \multicolumn{2}{|l|}{$\mathrm{D}$} & \multicolumn{2}{|c|}{ SD } \\
\hline & & $\mathrm{F}$ & $\%$ & $\mathrm{~F}$ & $\%$ & $\mathrm{f}$ & $\%$ & $\mathrm{f}$ & $\%$ \\
\hline 2 & $\begin{array}{l}\text { Parents believe that children will not be able learn English language } \\
\text { effectively in later education if they are introduced to schooling in the } \\
\text { mother tongue }\end{array}$ & 79 & 73.83 & 20 & 18.69 & 5 & 4.67 & 3 & 2.80 \\
\hline 3 & $\begin{array}{l}\text { Parents consider centres in which mother tongue instruction is undertaken as } \\
\text { a poor centre }\end{array}$ & 8 & 7.48 & 16 & 14.95 & 30 & 28.04 & 53 & 49.53 \\
\hline 5 & $\begin{array}{l}\text { Parents always resist the use of mother tongue in teaching their children and } \\
\text { wards }\end{array}$ & 89 & 83.18 & 10 & 9.35 & 4 & 3.74 & 4 & 3.74 \\
\hline 6 & $\begin{array}{l}\text { Some parents will prefer withdrawing their children and ward if the centre } \\
\text { insists on using the mother tongue as a medium of instruction }\end{array}$ & 33 & 30.84 & 29 & 27.10 & 25 & 23.36 & 20 & 18.69 \\
\hline 7 & Parents believe they cannot pay for learning in indigenous language & 87 & 81.31 & 13 & 12.15 & 4 & 3.74 & 3 & 2.80 \\
\hline 8 & Some parents love the mother tongue instructional policy & 10 & 9.35 & 21 & 19.63 & 34 & 31.78 & 42 & 39.25 \\
\hline
\end{tabular}


Table 4 shows the disposition of parents in the course of implementing the mother tongue instructional policy. It can be seen from the Table that the parents are negatively disposed to the use of mother tongue in teaching their children and wards. For instance it can be seen that most of the respondents (83.18\%) indicated that parents always resisting teaching their children and wards in the mother tongue and that $(63.55 \%)$ that the parents abhor the use of mother tongue instruction. They also indicated (73.83\%) that the parents were afraid that children may not be able learn English language effectively in later education if they are introduced to schooling in the mother tongue.

\section{Discussion}

The Universal Basic Education Act of 2004 described early childhood education (ECE), as the preprimary education given to children between ages one and five; as representing the first important step in achieving the goals of education for all (EFA). Ifakachukwu (2011) observed that a policy could be good but if it is not carefully and religiously implemented, it will become a mere paper work and that if pre-primary education is to serve its stated purposes of making the children to have an effective smooth transition from the home to the school; prepare the child for the primary level of education; inculcate social norms; inculcate in the child the spirit of enquiry and creativity; develop a sense of cooperation and team-spirit and really teach the children the rudiments of numbers, letters, colours, shapes, among others, it should be well supervised, staffed, equipped, financed and coordinated.

Consequently, research question 1 was posed to determine the level of awareness of ECCDE centre operators concerning the mother tongue instructional policy. The results showed that most of the respondents possess high level of awareness of the policy provisions while some of them possess a moderate level of awareness. The second research question was posed to find out the operational practices commonly adopted by the ECCDE centres in implementing the mother tongue instructional policy. The results showed opined that it cannot be said that the mother tongue instructional policy are been implemented in ECCDE centres under study. The results indicated that most of the respondents that all the children were being taught all subjects in the local language of their communities - Yoruba language while only very few of the respondents strongly agreed while $14.95 \%$ merely agreed. Some of the respondents indicated that they teach some subjects in Yoruba language while most even indicated that they find it difficult to teach colours, shapes and forms in the local language and some others indicated that the parents discourage the implementation of the mother tongue instructional policy by refusing that their children be given mother tongue instructions. Further, research question 3 was posed to investigate the challenges encountered by ECCDE centre management/operators in the implementation of the Mother tongue instructional policy. The results showed that the most noticeable challenges are those experienced from the government, the centre owners and the parents.

It was found according to most of the respondents that the government has just been paying lip service to the implementation of the policy and that whenever officials from the monitoring and inspectorate unit visited, they do not insist on the implementation of the policy. They also indicated that since the centres are mostly privately owned with basic interest in the income, and parent's vehemently resisting teaching their children and ward in mother tongue it may be difficult to implement the policy in their centres.

Finally research question 4 sought for the disposition of the parents and ECCDE centre operators toward the mother tongue instructional policy. The results showed that the parents were negatively disposed to the use of mother tongue in teaching their children and wards. Most of the respondents indicated that parents always resist teaching their children and wards in the mother tongue and that the parents abhor the use of mother tongue instruction. They also indicated that the parents were afraid that children may not be able learn English language effectively in later education if they are introduced to schooling in the mother tongue.

\section{Conclusion}

From the foregoing it is evident that the Mothe Tongue instructional policy is not being properly implemented in ECCDE centres in Ife Zone of Osun state. Reasons found for this include the disposition of the government, parents and the owners as well as the operators of such centres.

\section{Recommendations}

It is recommended that greater enlightenment should be made for the general public to understand the importance of the mother tongue instructional policy. Also the federal and State government need to improve their involvement in direct participation, policy monitoring and control of ECCDE centres. 


\section{References}

Ball, J (2010). Enhancing learning of children from diverse language backgrounds: Mother tongue-based bilingual or multilingual education in early childhood and early primary school years. UNESCO: Fairplay for children. Retrieved May 12, 2015 from http://fairplayforchildren.org/pdf/1291322781.pdf

Benson, C. (2005). The importance of mother tongue-based schooling for educational quality, Commissioned study for EFA Global Monitoring Report 2005

Cook, V. (2008). Second Language Learning and Language Teaching. London: Arnold. pp. 76-77. ISBN 978-0-34095876-6..

Dea, L. M., Basha, T. T. and Abera, N. A. (2013). Challenges in use of mother tongue based education as medium of instruction in primary school for quality enhancement: in case of Wolaita Zone Administration. Merit Research Journal of Education and Review 2(8), 152-162.

Ellis, R. (1997). Second Language Acquisition. Oxford Introductions to Language Study. Oxford, New York: Oxford University Press.ISBN 978-0-19-437212-1.

Gacheche, K.(2010). Challenges in implementing a mother tongue-based languagein-education policy: Policy and practice in Kenya. POLIS Journal, 4, 1 - 45

Khan, M. T. (2014). Education in Mother Tongue- A Children's Right. International Journal of Humanities and Management Sciences (IJHMS), 2(4), 148 - 164

Kosenen \& Young, (2009). Mother Tongue as Bridge Language of Instruction: Policies and Experiences in Southeast Asia. Bangkok, Thailand: SEAMEO

Magwa (2015). Attitudes towards the Use of Indigenous African Languages as Languages of Instruction in Education: A Case of Zimbabwe. Journal of Educational Policy and Entrepreneurial Research (JEPER), 2(1), 1-16

Maseko B. \& Dhlamini, N. (2014). Journal of Education and Practice, 5(6), 59 - 65.

Nwagbara, G. U. (2013). Indigenous Language News and the Marginalization of Some Ethnic Groups in the Nigerian Broadcast Media. Studies of Tribes and Tribals, 11(2), 153-160

OECD (2010) What Will It Take to Achieve the Millennium Development Goals? An International Assessment. USA: UNDP, 